\title{
The Stereoscopic Teaching Material Construction for the Innovative Practice Teaching of Intelligent Agricultural Machinery
}

\author{
Song xin \\ College of Engineering and Technology \\ Tianjin Agricultural University \\ Tianjin, China \\ songxin-tju@163.com \\ Shan Huiyong \\ College of Engineering and Technology \\ Tianjin Agricultural University \\ Tianjin, China \\ tjshy@sohu.com
}

\author{
Yang Lei \\ College of Engineering and Technology \\ Tianjin Agricultural University \\ Tianjin, China \\ yanglei2016@tjau.edu.cn \\ Li Yancong \\ College of Engineering and Technology \\ Tianjin Agricultural University \\ Tianjin, China \\ lyc65@163.com
}

\begin{abstract}
In view of the current demand target for the intelligent agricultural machinery talents in China, the construction project of stereoscopic teaching material which is integrated with innovative practice education system and course for the intelligent agricultural machinery is provided. The significance, construction scheme, connotation and manifestation, and the implementation process of the stereoscopic teaching material are discussed under the background of the education reform of the intelligent agricultural machinery innovative practice. By the construction of the stereoscopic teaching material, not only the innovative entrepreneurial and education skill for the teacher is enhanced, but also the learning enthusiasm for the student is stimulated and the ability of the scientific research, engineering practice, academic integration and collaborative innovation for the student is cultivated and enhanced.
\end{abstract}

Keywords-intelligent agricultural machinery; innovative education; stereoscopic teaching material; innovative practice

\section{INTRODUCTION}

At present, a new round of technological revolution and industry reform infuse a strong driving force for Chinese agricultural transformation and upgrading, and Chinese agriculture has entered a profound change in the era. In 2017, the CPC publish the No.1 document which clearly put forward to implement the wisdom agriculture engineering, promote intelligent agricultural machinery and agricultural EPC system network demonstration. And the scientific technological innovation is strengthened and the modern agriculture is led to the rapid development ${ }^{[1]}$. To promote the agricultural modernization, the material equipment and technical support must be strengthened.

Driven by the innovation of science and technology, the agricultural machinery is set as an important cornerstone for the development of modern agriculture under the background of the deep integration of agriculture and modern information technology. The training object and method of innovative talent will be changed to adapt to the demand of Chinese agricultural transformation. Under the traditional education mode, the division of the professional talent has fallen behind the situation. Then the innovation lead, initiative and interdisciplinary integration talent is demand subject for modern agriculture.

In order to train intelligent agricultural machinery talent with sustainable development quality such as engineering practice, disciplinary integration and collaborative innovation, it is imperative to carry out the innovative education in agricultural college, set the innovative training program as the curriculum and strengthen the innovative ability training. Among them, the compiling of multi-level, stereoscopic and practical teaching material is the main content of the innovative education curriculum construction and one of the key issues of the innovative education successful implementation. But the content of innovative teaching material in college and university often focus on simply piling up the basic concept of innovative thinking, the innovative method and training case. The discipline characteristic and target guidance is lacked; theory is emphasized but practice is neglected, and the systematic guidance for an innovative practice project from topic selection to the implementation of the entire process is lacked; the training method and case of scientific and innovative thinking is lacked especially. Besides, the traditional teaching material is relatively simple in the form, and cannot take into account the multi-dimensional curriculum objectives and multi-level teaching object. Then it is difficult to transfer knowledge to student accurately and efficiently simply by paper textbook on the text and teacher's oral presentation. So it is hard to stimulate the self-study enthusiasm.

The research was sponsored by the college teacher education reform and innovation development project for Tianjin Agricultural University (20170502). 
Therefore, the related problems of the stereoscopic teaching material construction in the intelligent agricultural machinery innovative practice education system are discussed, combined with the demand of talent under the development trend of intelligent agricultural machinery.

\section{THE SIGNIFICANCE OF STEREOSCOPIC TEACHING MATERIAL CONSTRUCTION}

The teaching material is the important carrier of educational idea, teaching content, method and means, and is the concrete embodiment of the reform achievement for the teaching content and curriculum system ${ }^{[2]}$. After years of research by the team members, it found that the traditional practice teaching and practice teaching material for agricultural machinery professional mainly exist the following problems:

\section{A. Single teaching material contents}

The contents always have several experiments aimed at a theoretical teaching content. In every experiments, the steps, tasks, and achieve the goal of the experimental is introduced in detail, or some simple experiment designs are put forward. So the teaching material content is more like a reference book, which be used for search how to solve problems. But the mode is hard to stimulate students' interest in learning, can't make it become the main body of students, and has violated the teaching purpose.

\section{B. Lacking of multidisciplinary integration in teaching material content}

In traditional practice teaching, practice teaching material often tend to be written for a course, its content involves only the theoretical knowledge of this course, rarely involves related courses or subjects. So it easy to cause the students cannot well establish the correlation among the multidiscipline or some courses, thus it unable to flexibly integrated use of professional knowledge.

\section{The major limitations in traditional practice teaching mode}

In traditional practice teaching, it also exists certain problems. Firstly, the practice teaching mode that similar to repeat what the book says can cause many students just stepby-step to complete a task, do not play their own subjective initiative, and not integrate their own thinking and innovative ideas into the practice training. Cause as a result, students only learned some basic knowledge in the textbook, but didn't get deeper practice ability. Secondly, the traditional teaching mode of "cramming", only pay attention to the development of narrow skills, while ignoring the cultivation of students' comprehensive ability such as engineering practice, disciplinary integration and collaborative innovation, and contrary to the nature of the practice teaching goal.

In 2002, China proposes the concept of the stereoscopic teaching material for the first time, based on the concept of modern educational idea and information network technology platform, which pay more attention to construct the teaching material system by educational technology than traditional teaching material. Through the integration of multi-media, multi-form, multi-purpose and multi-level teaching resource, using variety teaching method and providing variety teaching service, the new teaching scheme is designed for a multiple teaching according to the integration thinking. The purpose is to avert the disadvantage of providing a single teaching content in the traditional teaching material in the past, and to emphasize the total solution providing teaching resource to maximize meet the teaching and educational market needs. So the teaching reform can be promoted and the overall teaching quality and efficiency can be improved ${ }^{[3,4]}$.

In order to improve the implementation effect and quality of the teaching reform for the intelligent agricultural machinery innovative practice and the curriculum system construction, it is necessary to compile the stereoscopic teaching material which is oriented in the engineering practice, discipline integration and collaborative innovative ability cultivation. Combined with multi-level, stereoscopic, full coverage of innovative entrepreneurship education curriculum system, the stereoscopic teaching material can highlight the professional characteristic and fully embody the practical, innovative, frontier discipline and multi-disciplinary integration. As a result, the practice teaching space-time structure and activity mode is changed, and then the learning process and the actual engineering project are linked more closely. Then it is helpful to strengthen the autonomous learning mode and cooperative exploration, and stimulate the learning enthusiasm.

\section{THE CONSTRUCTION SCHEME AND IMPLEMENTATION PROCESS OF STEREOSCOPIC TEACHING MATERIAL FOR THE INTELLIGENT AGRICULTURAL MACHINERY INNOVATIVE PRACTICE}

The construction thinking of stereoscopic teaching material for the intelligent agricultural machinery innovative practice is that the development frontier of the intelligent agricultural machinery is closely followed in content, and the project implementation process is set as the main line. In the implementation of each aspect, the professional knowledge, key technology, ability training and the instructive theory for the innovative practice is educed, with strong practice and operational, innovative, discipline forefront and integration. In the form of carrier, the stereoscopic teaching material is composed by a set of paper teaching material, multi-form and multi-purpose structural subsidiary course and auxiliary teaching resource ${ }^{[5]}$.

\section{A. Construction scheme}

The basic framework of the construction of stereoscopic teaching material for the intelligent agricultural machinery innovative practice teaching is shown in Fig. 1. 


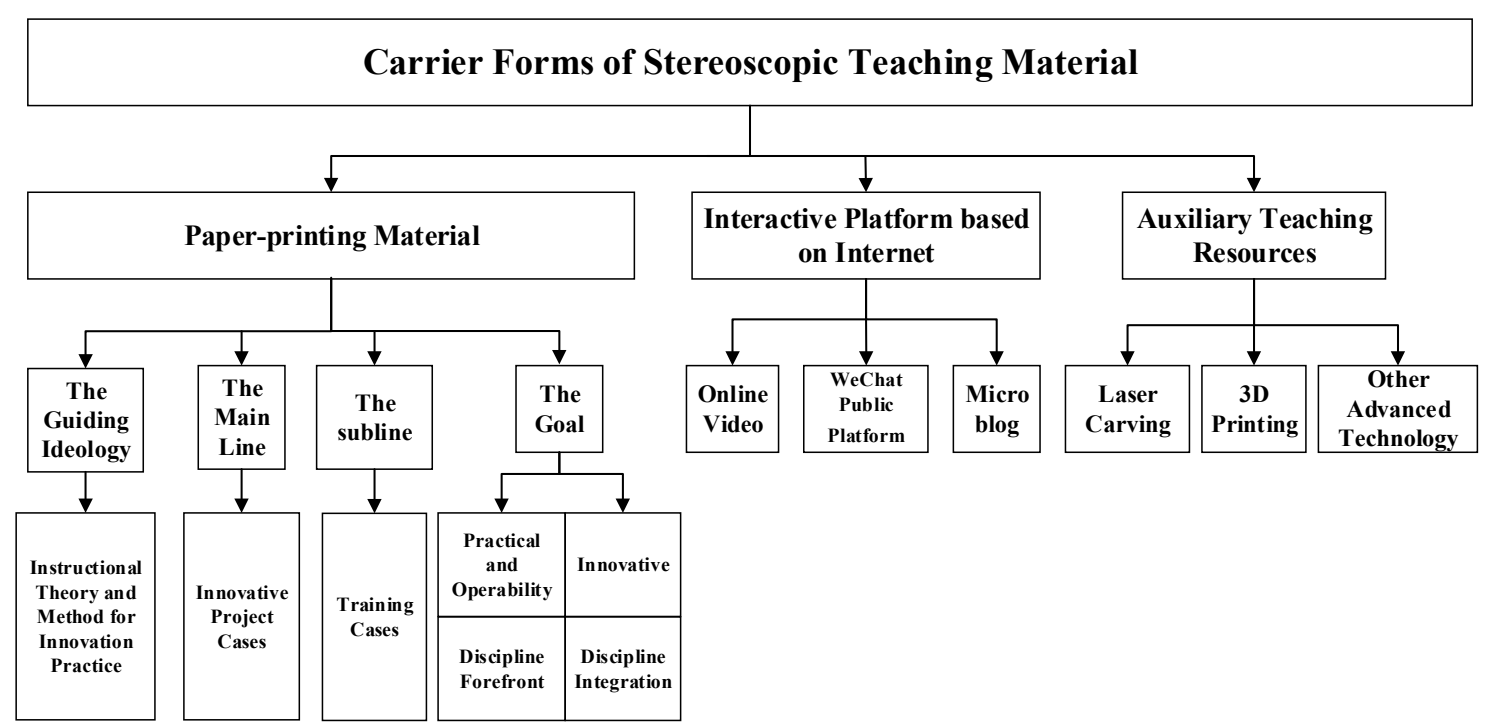

Fig. 1. The basic framework of the construction of stereoscopic teaching material for the intelligent agricultural machinery innovative practice teaching

(1) A number of innovative project and training case is made developmentally to form a series of relatively perfect theory and method to guide innovative practice.

(2) The intelligent agricultural machinery innovative practice is compiled in paper teaching material. The specific engineering project is set as an example, and the basic process of engineering innovative practice and each aspect of the theoretical knowledge, key technology, realization method and difficult breakthrough is expounded, fitted with the corresponding practice of training case.

(3) The multi-form, multi-purpose structured subsidiary course is made by Internet, information and multimedia technology. By online video, microblog and WeChat public platform and other forms, the platform for technology interaction and information sharing is built.

(4) The complete set of stereoscopic teaching material for the intelligent agricultural machinery innovative practice is made by auxiliary teaching resource using laser carving, 3D printing and other advanced technology, combined with the previously mentioned paper material and structural supporting course. It is helpful to use the relevant resource to teach and learn more flexible, and it can maximize meet the requirements of the teacher's teaching and student's learning, improve the quality of teaching and learning, promoting the reform of the teaching methods and teaching means by the stereoscopic presentation $^{[6]}$.

\section{B. Implementation process}

(1) Combined with the innovative practice experience and technology accumulation, the project example is set on the basis of absorbing domestic and foreign research achievement on the forefront. Furthermore, the necessary knowledge, technology and ability, which is needed for the implementation of the project selection process, project management and design, specific implementation, writing paper or technical report, project reply and exhibition, and other aspect, is summed up and concluded. As a result, a series of more perfect innovative practice guiding theory and method is formed.

(2) The paper version of the textbook "Intelligent agricultural machinery innovative practice course" is written, and the process of the project implementation is set as the main line to integrate the guidance theory and method of innovative practice. Different gradient training case for each instance of the project is provided to practice, so that the learning outcome can be test timely.

(3) The corresponding structural subsidiary course and auxiliary teaching resource is produced to form a complete set of stereoscopic teaching material draft for the intelligent agricultural machinery innovative practice.

(4) The complete set of stereoscopic teaching material is implemented in a small range to amend the exist problem.

(5) The academic leader, industry enterprise outstanding talent and teaching material construction team member are organized in a forum. On the one hand, the rationalization opinion and suggestion for teaching material is gathered, on the other hand the teaching material content, the overall quality and effectiveness is evaluated to put forward suggestion for improvement.

(6) Combined with the implementation effect, evaluation and rectify opinion, the teaching material is amended and improved. At last, the complete set of stereoscopic teaching material which is more perfect and practical is formatted for the intelligent agricultural machinery innovative proactive.

\section{CONClusion}

With the information education reform development, the stereoscopic teaching material which is more emphasis on the use of educational technology to construct the teaching material system than the tradition is set as the theme for the modern teaching material construction to promote the construction of the teaching content and curriculum system and 
the reform of the teaching method. Consequently, all the teacher and student benefit from it.

(1)Benefit for student: By using of the stereoscopic teaching material for the intelligent agricultural machinery innovative practice, it is helpful to teach and learn more flexible. Then the student's autonomous learning mode and cooperative exploration is strengthened. By teaching interaction, knowledge system and teaching focus for paper textbooks can be deeply understood. As a result, the enthusiasm for learning is stimulated greatly, and the ability of scientific research, engineering practice, discipline integration and collaborative innovation is cultivated and improved.

(2)Benefit for teacher: By writing and using of the stereoscopic teaching material for the intelligent agricultural machinery innovative practice, the teacher's innovative entrepreneurial education skill is enhanced. And the teacher is promoted to the enterprise to accumulate practical experience and enhance the practical ability. In addition, it also provides a strong support to the successful implementation of the stereoscopic teaching material and the successful reform of the training mode for the intelligent agricultural machinery innovative practice.

\section{ACKNOWLEDGMENT}

In this paper, the research was sponsored by the college teacher education reform and innovation development project for Tianjin Agricultural University (20170502).

\section{REFERENCES}

[1] Xinhua News Agency. In 2017, the CPC publish the No.1 document Further promote the structural reform of agricultural supply side is proposed [EB/OL]. http://news.xinhuanet.com/201702/05/c 1120413508.htm, 2017-02-05.

[2] $\mathrm{Xu}$ Hong. The multi-dimensional thinking of stereoscopic teaching material construction [J]. China Electric Power Education.2008, (125):79-80(In Chinese).

[3] Huang Huairong, Guo Fang. The design and development of stereoscopic teaching material [J]. Modern Educational Technology. 2008, 10:105-108(In Chinese).

[4] Liu Jing,Liu Yan.The Research and Practice of Three-dimensional Teaching Material System of E-Learning[J].Study of Computer Application in Education.2013.22:138-140(In Chinese).

[5] Zhang Xiaolan,Xing Yu. Construction and Practice of the mode on classroom teaching supported by Three-dimensional teaching materialTake the normal students' public courses Modern Education Technology for an example[J]. Modern Educational Technology.2011.21(8):38-41.

[6] Qiu Jifan,Wang Haichun, Wei Zhong, Zhou Xing. The construction of stereoscopic teaching material for excellent course- Digital Electronic Technology [J].Journal of Chengdu Aeronautic Vocational \& Technical College.2007,23(1):29-31(In Chinese). 